\title{
HUBUNGAN STRES KERJA DENGAN KELELAHAN PADA PERAWAT DENGAN METODE PENGUKURAN DASS 21 DAN IFRC
}

\author{
CORRELATION BETWEEN WORK STRESS AND FATIGUE ON NURSES WITH \\ MEASUREMENT METHOD DASS 21 AND IFRC \\ Viska Devintha Candra Kirana, Endang \\ Dwiyanti \\ Departemen Kesehatan dan Keselamatan Kerja Fakultas Kesehatan Masyarakat \\ Universitas Airlangga Surabaya \\ Email: viskaaa@hotmail.com
}

\begin{abstract}
The demands of nurses to treat patients resulted in increased work activities. Increased activity of this work can led to occupational stress that can cause fatigue. Fatigue can lead to degraded productivity and work accidents. The purpose of this study was conducted to determine and identify the frequency distribution of age and gender, as well as determine the relationship of job stress and fatigue. This research was an analytical study. Based on the data collection was an observational research using cross sectional approach. The study population was a nurse at the Menur Mental Hospital, duty on intermediate classrooms. The sample of this study was selected by random sampling and proportional random sampling. Data retrieval was divided into two, namely primary and secondary data. Technique primary data collection was using questionnaires, and secondary data was taken from the hospital profile and staffing data. Variables to be studied is the work stress and fatigue. Data was analyzed using statistical software descriptive statistics. Most of the nurses experiencing work stress at the normal rate of $69.2 \%$, and as much as $69.2 \%$ of nurses experienced fatigue at a low level. Results of statistical tests to determine the relationship between job stress and fatigue obtained value $p=0,000$ with a value of $\alpha=0.05$. So the $p$ value less than the $\alpha$ value $(p<\alpha)$, thus indicating that a significant relationship between job stress and fatigue. The conclusion that can be drawn from this study is that the majority of nurses who experience stress at a normal level, then will experience fatigue at a low level. It is better to do exercise regularly and refreshing periodically as a step taken to minimize stress and fatigue.
\end{abstract}

Keywords: Work Stress, Fatigue, DASS 21, IFRC 


\section{ABSTRAK}

Tuntutan kerja perawat untuk menangani pasien mengakibatkan aktivitas kerjanya meningkat. Peningkatan aktivitas kerja ini dapat mengakibatkan terjadinya stres kerja yang dapat menimbulkan kelelahan. Kelelahan dapat berakibat pada menurunnya produktivitas kerja serta terjadinya kecelakaan kerja. Tujuan penelitian ini dilakukan untuk mengetahui dan mengidentifikasi distribusi frekuensi usia dan jenis kelamin, serta mengetahui hubungan stres kerja dan kelelahan. Penelitian yang dilakukan merupakan penelitian analitik. Berdasarkan pengambilan data merupakan penelitian observasional dengan menggunakan pendekatan cross sectional. Populasi penelitian ini merupakan perawat pada Rumah Sakit Jiwa Menur Provinsi Jawa Timur yang bertugas pada ruang intermediate. Pengambilan sampel dilakukan dengan cara random sampling dan proportional random sampling. Pengambilan data dibagi menjadi dua, yakni data primer dan sekunder. Teknik pengambilan data primer menggunakan media kuisioner, sedangkan data sekunder diambil dari profil rumah sakit dan data kepegawaian. Variabel yang akan diteliti adalah stres kerja dan kelelahan. Untuk menganalisis data penelitian menggunakan bantuan software statistik deskriptif. Sebagian besar perawat yang mengalami stres kerja pada tingkta normal sebesar $69,2 \%$. Dan sebanyak $69,2 \%$ perawat mengalami kelelahan pada tingkat yang rendah. Hasil uji statistik untuk mengetahui hubungan antara stres kerja dan kelelahan diperoleh nilai $\mathrm{p}=0,000$ dengan nilai $\alpha=0,05$. Jadi nilai $\mathrm{p}$ lebih kecil dari nilai $\alpha(\mathrm{p}<\alpha)$, dengan demikian menunjukkan bahwa adanya hubungan yang bermakna antara stres kerja dengan kelelahan. Kesimpulan yang dapat ditarik dari hasil penelitian ini adalah mayoritas perawat yang mengalami stres pada tingkat normal, maka akan mengalami kelelahan pada pada tingkat yang rendah. Ada baiknya dilakukan olahraga secara rutin dan refreshing secara periodik sebagai langkah untuk meminimalisir stres dan kelelahan.

\section{Kata Kunci: Stres Kerja, Kelelahan, DASS 21, IFRC}

\section{PENDAHULUAN}

Semakin berkembangnya zaman, semakin tinggi pula tuntutan hidup yang harus dimiliki seseorang. Tuntutan hidup tidak hanya berasal dari diri sendiri, namun juga dari lingkungan sekitarnya. Jika seseorang tidak mampu untuk mengatasi tuntutan dalam hidupnya, maka besar kemungkinan orang tersebut akan mengalami stres yang dapat mengakibatkan gangguan kejiwaan.

Gangguan kejiwaan merupakan gangguan pada orang normal ditandai dengan kemurungan, kesedihan, kepatahan semangat yang ditandai dengan perasaan tidak sesuai, menurunnya kegiatan dan pesimisme menghadapi masa yang akan datang (Meta, 2011).

Dengan semakin meningkatnya orang yang mengalami stres dan berujung pada gangguan kejiwaan, maka kebutuhan akan pelayanan kesehatan khususnya rehabilitasi kejiwaan akan semakin bertambah dan meningkat. Hal tersebut mengakibatkan bertambahnya beban kerja pada perawat.
Semakin bertambahnya beban kerja pada perawat maka dapat mengakibatkan terjadinya stres kerja serta kelelahan yang dirasakan. Orang-orang yang mengalami gangguan kejiwaan membutuhkan penangan khusus hingga mereka dapat beraktifitas kembali secara normal. Dibutuhkan sumber daya manusia yang cukup berkompeten untuk menangani penyakit kejiwaan tersebut.

Pada tahun 2012 didapatkan data bahwa pasien gangguan jiwa di Provinsi Jawa Timur yang menjalani rawat inap mencapai 1.577.587 pasien. Dari data yang didapatkan tersebut, sangat besar kemungkinan jika jumlah pasien akan terus bertambah setiap tahunnya. Jika jumlah pasien bertambah tidak menutup kemungkinan bahwa beban kerja yang bisa menjadi sumber dari stres kerja serta kelelahan akan bertambah pula. Tuntutan kerja perawat yang tinggi mengakibatkan aktivitas kerjanya akan meningkat, sehingga waktu untuk beristirahat juga akan semakin berkurang. Hal tersebut dikarenakan, banyaknya 
jumlah pasien yang akan menerima pelayanan dari perawat.

Dari hasil penelitian sebelumnya yang dilakukan oleh Riza (2011) pada perawat Rumah Sakit mendapatkan hasil bahwa sebanyak $3,4 \%$ perawat mengalami kelelahan berat, $62,1 \%$ perawat mengalami kelelahan sedang, dan sisanya sebanyak $34,5 \%$ perawat mengalami kelelahan ringan. Sedangkan penelitian yang dilakukan oleh Anita (2011) didapatkan hasil bahwa $96 \%$ perawat mengalami kelelahan kerja pada tingkat yang ringan dan normal. Sisanya, sebanyak 4\% perawat mengalami kelelahan kerja pada tingkat yang berat.

Stres yang dialami oleh seseorang dapat dipengaruhi oleh tekanan internal dan eksternal. Yang dapat menjadi sumber tekanan secara internal antara lain kondisi fisik, perilaku, kognitif, emosional, dan lain sebagainya. Sedangkan sumber tekanan eksternal adalah lingkungan fisik, karakteristik pekerja, lingkungan sosial budaya, dan lain sebagainya. Jika seseorang melakukan pekerjaan melebihi kapasitasnya, maka dapat memungkinkan orang tersebut akan mengalami stres. Gejala yang dapat menimbulkan stres antara lain seperti otot mengencang, denyut jantung meningkat, pernafasan menjadi lebih cepat, dan lain sebagainya.

Sedangkan kelelahan adalah suatu mekanisame perlindungan tubuh agar tubuh terhindar dari kerusakan lebih lanjut sehingga terjadi pemulihan setelah istirahat. Kelelahan diatur secara sentral oleh otak. Istilah kelelahan biasanya menunjukkan kondisi yang berbeda-beda dari setiap individu, tetapi semuanya bermuara pada kehilangan efisiensi dan peenurunan kapasitas kerja serta ketahanan tubuh. Kelelahan diklasifikasikan dalam dua jenis, yaitu kelelahan otot atau perasaan nyeri pada otot, dan kelelahan umum. Kelelahan umum biasanya ditandai dengan berkurangnya kemauan untu bekerja (Tarwaka, 2004).

Faktor yang dapat mengakibatkan kelelahan umumnya berkaitan dengan sifat kerja yang monoton, stasiun kerja yang tidak ergonomis, intensitas kerja dan ketahanan kerja mental dan fisik yang tinggi, cuaca lokasi kerja, pencahayaan, kebisingan, getaran serta lingkungan kerja lain yang tidak memadai dan ekstrim, faktor psikologis seperti rasa tanggung jawab, ketegangan dan konflik di tempat kerja, rasa nyeri yang dirasakan, circadian rhytem, nutrisi, serta waktu kerja dan istirahat yang tidak tepat.

Asuhan keperawatan yang dilakukan oleh perawat di rumah sakit jiwa berbeda dengan perawatan di rumah sakit umum. Perawatan serta pengawasan terhadap pasien sepenuhnya dilakukan oleh perawat yang sedang bertugas, sedangkan pihak keluarga hanya diperkenankan untuk sesekali berkunjung. Perawat harus mampu mengerti dan memahami apa yang diingkan oleh pasien tersebut. Perawat yang mendapatkan beban kerja secara berlebihan dapat menimbulkan stres kerja yang dapat berdampak pada timbulnya kelelahan. Dengan adanya kelelahan yang dialami oleh perawat maka dapat menurunkan produktifitas saat melayani pasien.

Dari penelitian yang dilakukan sebelumnya banyak peneliti yang menganalisa mengenai faktor-faktor yang berhubungan dan menyebabkan terjadinya kelelahan. Dengan adanya identifikasi masalah yang ada penulis tertarik untuk meneliti mengenai salah satu faktor kelelahan yakni stres kerja serta hubungannya antara stres kerja dan kelelahan yang terjadi pada perawat yang bekerja di instalasi rawat inap kelas intermediate (ruang gelatik, kenari, dan flamboyan) di Rumah Sakit Jiwa Menur Provinsi Jawa Timur.

\section{METODE PENELITIAN}

Lokasi penelitian dilaksanakan di Rumah Sakit Jiwa Menur Provinsi Jawa Timur. Penelitian yang akan dilakukan merupakan penelitian analitik. Penelitian ini adalah untuk mengetahui hubungan dari dua variabel, yakni variabel dependen dan variabel independen. Variabel dependen dalam penelitian ini adalah

kelelahan, sedangkan variabel independen yang digunakan adalah stres kerja. Berdasarkan metode pengumpulan datanya, penelitian ini merupakan penelitian 
observasional, sedangkan dari segi waktu penelitian merupakan penelitian cross sectional. Populasi didalam penelitian ini adalah seluruh perawat pelaksana pada bagian rawat inap kelas intermediate pada ruang gelatik, kenari dan flamboyan yang berada pada Rumah Sakit Jiwa Menur Provinsi Jawa Timur. Besar sampel yang akan digunakan diambil menggunakan rumus random sampling slovin dan proportional random sampling. Besar sampel yang menjadi responden adalah 26 orang perawat. Yang terdiri dari 10 orang perawat shift pagi, 8 orang perawat shift siang dan 8 orang perawat shift malam.

Teknik pengumpulan data menggunakan metode pengisian kuisioner. Metode DASS 21 (Depression Anxiety Stress Scale 21) merupakan metode yang digunakan untuk pengukuran stres kerja yang dialami dalam melakukan aktivitas pekerjaannya. Sedangkan metode IFRC (Industrial Fatigue Research Committe) digunakan untuk pengukuran kelelahan kerja yang dirasakan oleh pekerja dalam melakukan pekerjaannya.

DASS 21 (Depression Anxiety Stress Scale 21) merupakan alat ukur subjektif yang dibentuk untuk mengukur status emosional negatif dari depresi, kecemasan, dan stres. Hasil dari pengukuran akan diklasifikasikan pada lima kategori, yakni normal, ringan, sedang, parah, dan sangat parah.

IFRC (Industrial Fatigue Research Committe) mengandung tiga puluh macam perasaan kelelahan yang dirasakan, merupakan alat ukur tingkat kelelahan subjektif. IFRC menggunakan empat skala likert yang terbagi menjadi sangat sering, sering, kadang - kadang, dan tidak pernah. Dari total skor yang didapatkan akan diklasifikasikan dalam empat kategori, yakni kelelahan rendah, sedang, tinggi, dan sangat tinggi.

\section{HASIL PENELITIAN}

Hasil penelitian yang didapatkan meliputi usia, jenis kelamin, stres kerja, dan kelelahan perawat di instalasi rawat inap kelas intermediate (ruang gelatik, kenari, dan flamboyan) Rumah Sakit Jiwa Menur
Provinsi Jawa Timur. Berikut ini merupakan tabel distribusi responden berdasarkan usia yang dibagi menjadi lima kelompok. Berdasarkan data distribusi ini dapat diketahui bahwa sebagian besar perawat berada pada usia produktif untuk bekerja.

Tabel 1. Distribusi Usia Responden

\begin{tabular}{|l|c|c|}
\hline $\begin{array}{l}\text { Gol. Usia } \\
\text { (Tahun) }\end{array}$ & Frekuensi & $\begin{array}{c}\text { Persentase } \\
\text { (\%) }\end{array}$ \\
\hline $15-24$ & 1 & 3,8 \\
\hline $25-34$ & 14 & 53,8 \\
\hline $35-44$ & 9 & 34,6 \\
\hline $45-54$ & 2 & 7,7 \\
\hline$>55$ & 0 & 0 \\
\hline Total & 26 & 100 \\
\hline
\end{tabular}

Sedangkan data distribusi jenis kelamin perawat yang menjadi responden dapat dilihat pada tabel berikut ini (tabel 2).

Tabel 2. Distribusi Responden Menurut Jenis Kelamin

\begin{tabular}{|l|c|c|}
\hline Jenis Kelamin & Frekuensi & $\begin{array}{c}\text { Persentase } \\
(\%)\end{array}$ \\
\hline Laki-laki & 15 & 57,7 \\
\hline Perempuan & 11 & 42,3 \\
\hline \multicolumn{1}{|c|}{ Total } & 26 & 100 \\
\hline
\end{tabular}

Metode pengukuran stres kerja menggunakan kuisioner DASS 21 mendapatkan hasil yang diintrepretasikan menjadi lima kategori stres kerja. Hasil dari pengukuran dapat dilihat pada tabel 3 .

Tabel 3. Distribusi Stres Kerja yang Terjadi pada Responden

\begin{tabular}{|l|c|c|}
\hline Stres Kerja & Frekuensi & $\begin{array}{c}\text { Persentase } \\
(\mathbf{\%})\end{array}$ \\
\hline Normal & 18 & 69,2 \\
\hline Ringan & 3 & 11,5 \\
\hline Sedang & 3 & 11,5 \\
\hline Parah & 1 & 3,8 \\
\hline $\begin{array}{l}\text { Sangat } \\
\text { Parah }\end{array}$ & 1 & 3,8 \\
\hline Total & 26 & 100 \\
\hline
\end{tabular}

Dari hasil pengukuran stres kerja pada 26 perawat di dapatkan hasil bahwa sebanyak $18(69,2 \%)$ orang perawat mengalami stres pada tingkat yang normal. Sedangkan pada tingkat stres yang sangat parah hanya terdapat $1 \quad(3,8 \%)$ perawat yang 
mengalaminya.

Pengukuran kelelahan yang dilakukan dengan menggunakan metode kuisioner IFRC yang terdiri dari 30 pertanyaan mengenai pelemahan kegiatan, pelemahan motivasi, dan gambaran kelelahan fisik. Pada pengukuran tersebut mendapatkan hasil perhitungan dan pengkategorian yang diintrepretasikan pada tabel 4 .

Tabel 4. Distribusi Kelelahan yang Terjadi pada Responden

\begin{tabular}{|l|l|c|}
\hline \multicolumn{1}{|c|}{ Kelelahan } & Frekuensi & $\begin{array}{c}\text { Persentase } \\
(\mathbf{\% )}\end{array}$ \\
\hline Rendah & 18 & 69,2 \\
\hline Sedang & 6 & 23,1 \\
\hline Tinggi & 2 & 7,7 \\
\hline Sangat Tinggi & 0 & 0 \\
\hline Total & 26 & 100 \\
\hline
\end{tabular}

Dari hasil pengukuran kelelahan yang terintrespretasikan pada tabel 4, maka diketahui bahwa sebagian besar perawat 18 $(69,2 \%)$ mengalami kelelahan pada tingkat yang rendah. Sedangkan perawat yang mengalami tingkat kelelahan sedang dan tinggi sebanyak $6(23,1 \%)$ dan

$2(7,7 \%)$ orang. Pada penelitian ini, tidak ada perawat yang mengalami kelelahan pada tingkat yang sangat tinggi. Berikut ini merupakan tabel distribusi berdasarkan hubungan antara stres kerja dengan kelelahan pada perawat yang dianalisis menggunakan software uji statistik.

Tabel 5. Distribusi Tabulasi Silang Stres Kerja dan Kelelahan pada Responden

\begin{tabular}{|c|c|c|c|c|}
\hline \multirow[t]{2}{*}{ Stress } & \multicolumn{3}{|c|}{ Kelelahan } & \multirow[t]{2}{*}{ Tota } \\
\hline & $\mathbf{R}$ & $\mathbf{S}$ & $\mathbf{T}$ & \\
\hline Normal & 17 & 1 & 0 & 18 \\
\hline Ringan & 0 & 3 & 0 & 3 \\
\hline Sedang & 1 & 1 & 1 & 3 \\
\hline Parah & 0 & 1 & 0 & 1 \\
\hline Total & 18 & 6 & 1 & 25 \\
\hline
\end{tabular}

Dari data yang telah tersaji pada tabel distribusi tersebut, menunjukkan bahwa perawat yang mengalami stres pada tingkat yang normal, berada pada tingkat kelelahan yang rendah. Perawat yang mengalami stres pada tingkat yang ringan, berada pada tingkat kelelahan yang sedang. Demikian pula dengan perawat yang mengalami stres pada tingkat yang sangat parah, berada pada tingkat kelelahan yang tinggi pula.

Hasil analisa hubungan menggunakan software statistik yang dilakukan untuk mengetahui hubungan antara stres kerja dengan kelelahan diperoleh nilai $p=0,000$. Dengan demikian, menunjukkan bahwa stres kerja dan kelelahan memiliki hubungan yang bermakna.

\section{PEMBAHASAN}

Stres yang dialami oleh seseorang diperngaruhi oleh tekanan internal dan eksternal. Seperti kondisi fisik, perilaku, lingkungan fisik, karakteristik pekerja, lingkungan sosial budaya, dan lain sebagainya (Sedarmayanti, 2011).

Stres pada tingkat yang normal biasanya hanya terjadi dalam waktu beberapa menit. Stres pada tingkat ringann biasanya terjadi beberapa jam, situasi ini tidak akan menimbulkan penyakit kecuali jika dihadapi secara terus menerus. Stres

pada tingkat sedang dan stres pada tingkat berat dapat memicu terjadinya penyakit, hal tersebut dapat terjadi karena stres telah dihadapi lebih dari beberapa jam hingga hari, sedangkan stres pada tingkat parah dan sangat parah merupakan stres kronis yang terjadi lebih dari beberapa minggu hingga beberapa tahun.

Perawat pada penelitian ini sebagian besar mengalami tingkat stres yang normal, dimana tingkat stres ini hanya berlangsung sesaat. Hal tersebut dapat mungkin terjadi karena perawat dapat mengendalikan atau memanajemen stres. Pasien pada rawap inap kelas intermediate Rumah Sakit Jiwa Menur Provinsi Jawa Timur merupakan pasien pada tahapan pengarahan dan persiapan pulang, sehingga pasien lebih mudah diarahkan dan dibimbing. Hal tersebut dapat menjadi salah satu faktor yang dapat mempengaruhi stres yang terjadi pada perawat.

Menurut Sedarmayanti (2011) kelelahan kerja merupakan suatu pola yang timbul pada suatu keadaa, yang secara umum terjadi pada setiap orang, yang telah tidak sanggup lagi untuk melakukan kegiatan.

Sama halnya dengan stres kerja, perawat pada rawat inap kelas intermediate 
sebagian besar mengalami kelelahan pada tingkat yang rendah.

Dimana, perawat tidak memiliki tugas terlalu berat karena pasien pada kelas intermediate sudah mudah untuk diarahkan dan diajak untuk bekerja sama. Dengan demikian, perawat dapat bekerja dengan lebih santai tanpa perlu mengeluarkan banyak energi.

Dari data distribusi pada tabel 5 yang merupakan hasil tabulasi silang antara stres kerja dengan kelelahan, dilakukan uji statistik. Menurut hasil uji statistik yang telah dilakukan antara hubungan stres kerja dengan kelelahan diperoleh nilai $\mathrm{p}=0,000$ dengan $\alpha=0,05$ maka nilai $\mathrm{p}$ lebih kecil dari $\alpha(\mathrm{p}<\alpha)$. Sehingga dapat disimpulkan bahwa stres kerja memiliki hubungan yang bermakna dengan kelelahan. Hasil penelitian ini didukung dengan hasil penelitian sebelumnya yang dilakukan oleh Ngasdianto (2015) yang menunjukkan bahwa sebanyak $78,8 \%$ pekerja mengalami kelelahan dengan tingkat stres kerja sedang, dibuktikan pula dengan perhitungan statistik yang memiliki hubungan kuat dengan nilai contingency coefficient sebesar 0,600 .

Hubungan yang dimiliki oleh stres kerja dan kelelahan merupakan hubungan yang searah. Perawat yang mengalami stres kerja pada tingkatan normal akan mengalami kelelahan pada tingkat yang normal. Demikian pula pada perawat yang mengalami stres pada tingkat yang sangat parah akan mengalami kelelahan pada tingkat yang tinggi pula.

Stres kronis berpengaruh terhadap perasaan kelelahan kerja pada urutan pertama sedangkan pengukuran waktu reaksi stres akut berpengaruh pada urutan kegita dan stres kronis pada urutan kelima. Stres dapat berpengaruh terhadap kelelahan kerja, namun tingkat pengaruhnya tidak sama bagi setiap pekerja (Sedarmayanti, 2011).

\section{SIMPULAN DAN SARAN}

Dari hasil penelitian yang telah dilakukan pada perawat ruang rawat inap kelas intermediate dapat diketahui bahwa
Sebanyak $69,2 \%$ atau 18 orang perawat memiliki tingkat stres kerja normal. Selanjutnya, mayoritas perawat pada instalasi rawat inap ruang gelatik, kenari, dan flamboyan mengalami kelelahan kerja pada tingkat yang rendah yakni sebesar $69,2 \%$ atau sebanyak 18 orang. Dari hasil uji statistik dapat diketahui bahwa hubungan antara stres kerja dan kelelahan kerja memiliki nilai $\mathrm{p}=0,000$ yang menunjukkan bahwa adanya hubungan yang bermakna antara stres kerja dan kelelahan.

\section{SARAN}

Dapat diberikannya ekstra fooding pada perawat saat relaksasi yang bertujuan untuk pemulihan energi sehingga dapat menekan timbulnya kelelahan. Selain itu dapat melakukan streacing untuk melemaskan otot setelah melakukan pekerjaan atau kegiatan agar terhindar dari timbulnya kelelahan pada otot setelah berkontraksi. Dan dapat melakukan relaksasi atau refreshing dimana seseorang dapat berfikir tentang suatu masalah dan merenungkannya dengan lebih tenang, dan sebagai wadah untuk melepas penat sehingga dapat meminimalisirkan terjadinya stres dan kelelahan.

\section{DAFTAR PUSTAKA}

Achmad, Fandi. 2015. Analisa Beban Kerja Mental Untuk Menentukan Jumlah Perawat Optimal (Studi Kasus Pada IGD RSPAU dr. S. Harjo Lukito). Skripsi. Yogyakarta: Universitas Islam Negeri Sunan Kalijaga.

Dinas Kesehatan Provinsi Jawa Timur. 2013. Profil Kesehatan Provinsi Jawa Timur Tahun 2012. Surabaya: Dinas Kesehatan Provinsi Jawa Timur.

Kasmarani, Murni Kurnia. 2012. Pengaruh Beban Kerja Fisik Dan Mental Terhadap Stres Kerja Pada Perawat Di Instalasi Gawat Darurat (IGD) RSUD Cianjur. Jurnal Kesehatan Masyarakat; Vol.1, 2:767-776.

Kurniawati, Dian., Solikhah. 2012. Hubungan Kelelahan Kerja Dengan Kinerja Perawat Di Bangsal Rawat 
Inap Rumah Sakit Islam Fatimah Kabupaten Cilacap. Jurnal Kesehatan Masyarakat UAD; Vol. 6, 2: $162-232$.

Lovibond, S.H., P.F. Lovibond. 1995. Manual For The Depression Anxiety \& Stress Scale. $2^{\text {nd }}$ Ed. Sydney: Psychology Foundation.

Luthfiyah, Annisa Nur. 2015. Analisis Perbedaan Motivasi, Beban Kerja Mental, Dan Kinerja Antara Perawat Di Pelayanan Rawat Inap Dengan Rawat Jalan (Studi Kasus Rumah Sakit Islam Siti Aisyah Madiun). Skripsi. Surabaya: Universitas Airlangga.

Maharja, Rizky. 2015. Hubungan Beban Kerja, Shift Kerja, Dan Asupan Kalori Dengan Kelelahan Kerja (Studi Pada Perawat Instalasi Rawat Inap di RSU Haji Surabaya). Skripsi. Surabaya: Universitas Airlangga.

Maurits, Lientje Setyawati K. 2010. Selintas Tentang Kelelahan Kerja. Yogyakarta: Amara Books.

Mayasari, Anita. 2011. Perbedaan Tingkat Kelelahan Perawat Wanita. Jurnal Kesehatan Masyarakat UNS; Vol. 7, 1: 28-34.

Ngasdianto. 2015. Hubungan Karakteristik Individu, Beban Kerja, Status Gizi, Dan Stress Kerja Dengan Kelelahan Kerja (Studi Pada Pekerja EEN Production). Skripsi. Surabaya: Universitas Airlangga.

Oesman, Titin Isna., Risma Adelina Simanjuntak. 2011. Hubungan Faktor Internal Dan Eksternal Terhadap Kelelahan Kerja Melalui Subjective Self Rating Test. Proceeding $11^{\text {th }}$ National Conference of Indonesian Ergonomics Society 2011; ISSN: 2088-9488.

Sedarmayanti. 2011. Tata Kerja dan Produktivitas Kerja, Suatu Tinjauan Dari Aspek Ergonomi Atau Kaitan Antara Manusia Dengan Lingkungan Kerjanya. Bandung: CV. Mandar Maju.

Tarwaka, Solichul HA. Bakri, Lilik Sudiajeng. 2004. Ergonomi Untuk Keselamatan, Kesehatan Kerja dan
Produktivitas. Surakarta: UNIBA PRESS.

Tejada, Jeffry J., Joyce Raymond B. Punzalan. 2012. On The Misuse Of Slovin's Formula. The Philippine

Statistican Journal; Vol. 61, 1: 129136.

Winarsunu, Tulus. 2008. Psikologi Keselamatan Kerja. Malang: UMM PRESS.

Yuliana, Eka. 2013. Hubungan Shift Kerja, Karakteristik Individu, dan Faktor Psikologi dengan Kelelahan Kerja Subyektif (Studi Pada Pekerja Helper PT. PJB UPHT Gresik). Skripsi. Surabaya: Universitas Airlangga. 
JURNAL ILMIAH KESEHATAN MEDIAHUSADA | VOLUME 06/NOMOR 01/MARET 2017 